Research Article

\title{
Transient Study on the HTR-PM with TINTE-vPower Coupling Code Package
}

\author{
Jun Sun, Ximing Sun, and Yanhua Zheng \\ Institute of Nuclear and New Energy Technology, Collaborative Innovation Center of Advanced Nuclear Energy Technology, \\ Key Laboratory of Advanced Reactor Engineering and Safety of Ministry of Education, Tsinghua University, Beijing 100084, \\ China
}

Correspondence should be addressed to Yanhua Zheng; zhengyh@mail.tsinghua.edu.cn

Received 11 November 2019; Accepted 25 February 2020; Published 25 August 2020

Guest Editor: Han Zhang

Copyright (C) 2020 Jun Sun et al. This is an open access article distributed under the Creative Commons Attribution License, which permits unrestricted use, distribution, and reproduction in any medium, provided the original work is properly cited.

\begin{abstract}
The high-temperature gas-cooled reactor pebble-bed module (HTR-PM) nuclear power plant consists of two nuclear steam supply system modules, each of which drives the steam turbine by the superheated steam flow and is fed by the heated-up water flow. The shared steam/water system induces mutual effects on normal operation conditions and transients of the nuclear power plant, which is worthy of safety concerns and intensive study. In this paper, a coupling code package was developed with the TINTE and vPower codes to understand how the HTR-PM operated. The TINTE code was used to analyze the reactor core and primary circuit, while the vPower code simulated the steam/water flow in the conventional island. Two TINTE models were built and coupled to one vPower model through the data exchange in the steam generator models. Using this code package, two typical transients were simulated by decreasing the primary flow rate or introducing the negative reactivity of one module. Important parameters, including the reactor power, the fuel temperature, and the reactor inlet and outlet helium temperatures of two modules, had been studied. The calculation results preliminarily proved that this code package can be further used to evaluate working performance of the HTR-PM.
\end{abstract}

\section{Introduction}

Modular high-temperature gas-cooled reactor (HTR) is well-known for the high safety, high efficiency, and processing heat applications capability. A commercial-scale 200 MWe pebble-bed modular high-temperature gas-cooled reactor (HTR-PM) has been designed and is now under construction in Shandong Province, China [1]. Most of the construction and installation work have been finished, and the connection to the electric grid will be expected in the end of 2020

The HTR-PM nuclear power plant (NPP) consists of two nuclear steam supply system (NSSS) modules, each of which contains independent reactor core, steam generator (SG), and passive reactor cavity cooling system (RCCS). The steam generated in two NSSS modules is supplied to one steam turbine [2]. After following through the condenser and deaerator, the water is pumped by two pumps, respectively, and fed back to two SGs again. Furthermore, the $600 \mathrm{MWe}$ commercial NPP with six similar NSSS modules and only one steam turbine is in the standard design phase. With this typical multimodule design, the transient or perturbation in one module will inevitably influence the operating features of other modules. Study on this coupling or interaction characteristics is important for further understanding and safe operation of the plant.

Engineering simulators have been developed to study the operating features of multimodule HTRs, especially for the intermodule influences during power load regulations or accidents [3, 4]. Benefited from the full-scope models and real-time simulations, engineering simulators can present coupled dynamic behaviors of the whole NPP by well-balanced computational cost and accuracy. In the integral supporting system of vPower code, reactor core models are simplified, while appropriate models of helium blowers, SGs, RCCSs, secondary systems, control systems, and electric 
system are coupled and managed in data transfer [5]. Without adequate detailed reactor core model, the vPower code of engineering simulator can only match the main parameters of the NPP and loses accuracies of distribution parameters.

To further improve the simulation accuracy, a coupling code package was developed with the TINTE and vPower codes. TINTE code is used to carry out the analysis of reactor core and primary circuit, while vPower code performs the secondary circuit calculation, including the primary side of the SGs. These two codes are connected through components of SGs. In this paper, two cases, including the primary flow rate decrease and the reactivity introduction of one module, were simulated with this code package. The phenomena in two modules, including some important parameters such as the reactor power, the fuel temperature, and the helium temperatures, were studied.

HTR-PM is shortly described in Section 2. Sections 3 and 4 provide description of the TINTE code and vPower code, and the coupling method between different circuits with these two codes is shortly discussed in Section 5. The calculation results are presented in Section 6. Finally, Section 7 presents the summary and conclusion.

\section{HTR-PM}

As mentioned above, there are two pebble-bed modular reactors in the HTR-PM NPP coupling with one steam turbine generators, whose total power is $500 \mathrm{MWt}$ and its electrical efficiency is about $42 \%$. For each reactor module, it consists of a high-temperature pebble-bed reactor and a once-through steam generator, as well as its connecting horizontal coaxial tube. The helium goes through the reactor core and is heated up to $750^{\circ} \mathrm{C}$, then transfers the heat to the secondary circuit water in the SG, and finally produces the high-pressure superheated steam. The helium at the SG outlet is cooled to about $250^{\circ} \mathrm{C}$ by the secondary circuit water. Then, this cold helium, driven by the helium blower, enters the reactor again through the outer annular channel of the coaxial duct $[6,7]$. Each equilibrium state reactor core has an average in height of $11 \mathrm{~m}$ and a diameter of $3.0 \mathrm{~m}$, which is a randomly packed pebble bed by roughly 420,000 spherical fuel elements.

The flow diagram of power conversion is shown in Figure 1, and the key parameters are provided in Table 1.

\section{TINTE Code and Model}

3.1. TINTE Code. The TINTE (TIme-dependent Neutronics and TEmperatures) is a special-designed and well-developed code by the Research Center Jülich to evaluate the nuclear and thermal transient behavior of pebble-bed high-temperature gas-cooled reactors. The performance of TINTE has been validated by the well-known open/blind benchmarks [8-11] and has been widely used in the pebble-bed hightemperature reactor design [12-14], such as the HTR-PM in China and PBMR in South Africa. VSOP99 (also developed for pebble-bed high-temperature gas-cooled reactor by the Research Center Jülich) is used to prepare state parameters, e.g., the cross sections, the power, and burnup histories, for TINTE calculation. There are several computational modules in TINTE to consider the complex multiphysics coupling effect in the pebble-bed high temperature reactor, such as the $2 \mathrm{D}$ neutronic diffusion module, $2 \mathrm{D}$ thermal-hydraulic module, the corrosion module, and the automatic control module. In this work, we focus on the thermal-hydraulic module, whose conservation equations and main correlations are as follows $[15,16]$.

(1) Pebble-bed heat conservation equation:

$$
\frac{\partial}{\partial t}(1-\varepsilon) \rho_{s} c_{s} T_{s}=\nabla(1-\varepsilon) \lambda_{f} \nabla T_{s}+q_{s}+\alpha\left(T_{g}-T_{s}\right),
$$

where the term $q_{s}$ and $\alpha\left(T_{g}-T_{s}\right)$ represent the heat flux from the fuel element and the convective heat transfer term between the pebble bed and coolant helium, respectively. $\lambda_{f}$ is the effective thermal conductivity, which considers the effects of radiation, gas and solid conduction, and contact conduction. The detail discussion about the correlations of effective thermal conductivity in the pebble-bed region could be found in [17-21].

(2) Helium continuity equation:

$$
\nabla \vec{u}=0
$$

(3) Helium momentum equation:

$$
\nabla p-\rho_{g} \vec{g}+W \vec{u}=0
$$

where the resistance coefficient $W$ could be determined as follows [22]:

$$
\begin{aligned}
& W=\Psi \cdot \frac{(1-\varepsilon)|\vec{u}|}{\varepsilon 2 d} \\
& \Psi=\frac{320}{(\operatorname{Re} / 1-\varepsilon)}+\frac{6}{(\operatorname{Re} / 1-\varepsilon)^{0.1}} .
\end{aligned}
$$

(4) Helium energy equation:

$$
\frac{\partial}{\partial t} \rho_{g} c_{g} T_{g}+\nabla\left(\vec{u} \rho_{g} c_{g} T_{g}\right)=\nabla \lambda_{g} \nabla T_{g}+\alpha\left(T_{s}-T_{g}\right),
$$

where the heat transfer coefficient of the surface of spherical fuel elements could be calculated, according to the German safety guide KTA3102.2 [23].

$$
N u=1.27 \times \frac{\operatorname{Pr}^{1 / 3}}{\varepsilon^{1.18}} \operatorname{Re}^{0.36}+0.033 \times \frac{\operatorname{Pr}^{1 / 2}}{\varepsilon^{1.07}} \operatorname{Re}^{0.86} .
$$

3.2. TINTE Model of HTR-PM. The calculation models for the HTR-PM have been established based on some reasonable approximations and simplifications. The $2 \mathrm{D}$ heat conduction and gas convection model of HTR-PM reactor is 


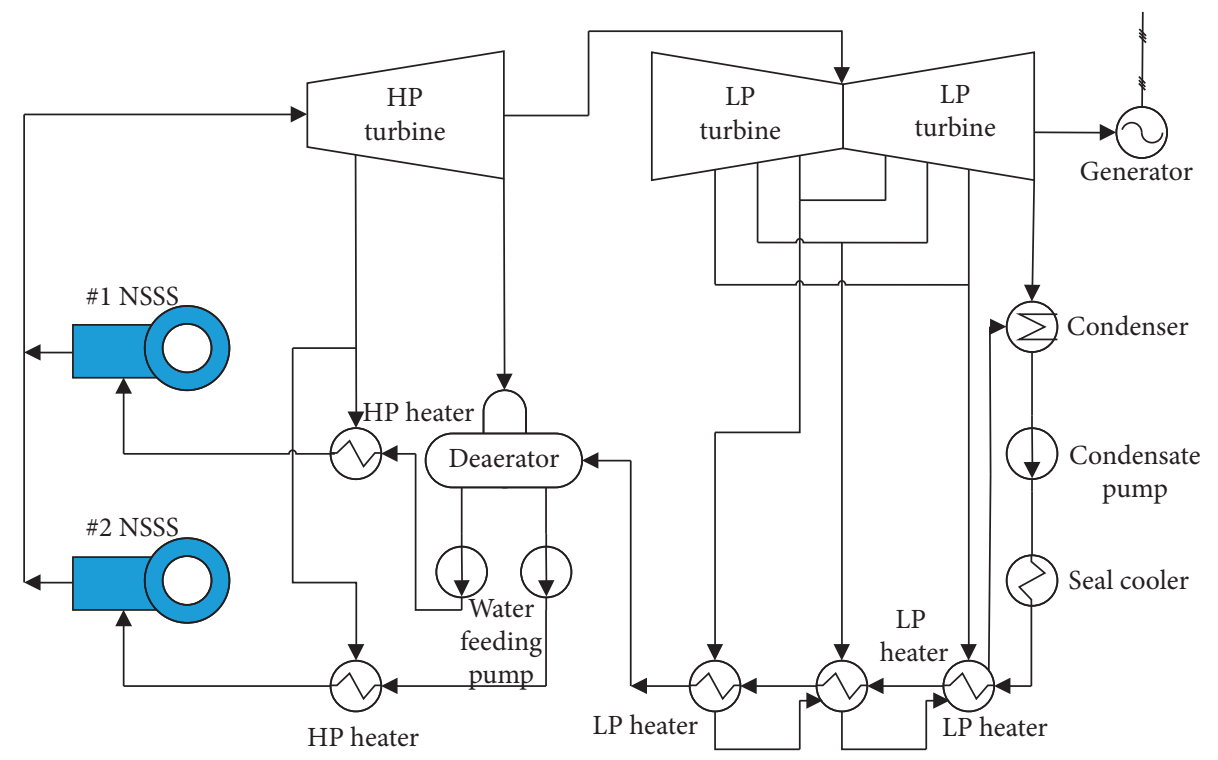

FIGURE 1: Flow diagram of power conversion [3].

TABle 1: Main design parameters of the HTR-PM [2].

\begin{tabular}{lc}
\hline Parameter & Value \\
\hline Reactor total thermal power $(\mathrm{MWt})$ & $2 \times 250$ \\
Rated electrical power (MWe) & 210 \\
Average core power density $\left(\mathrm{MW} / \mathrm{m}^{3}\right)$ & 3.22 \\
Net electrical efficiency $(\%)$ & 42 \\
Primary helium pressure $(\mathrm{MPa})$ & 7 \\
He temperature at reactor inlet/outlet $\left({ }^{\circ} \mathrm{C}\right)$ & $250 /$ \\
& 750 \\
Primary helium flow rate $(\mathrm{kg} / \mathrm{s})$ & 96 \\
Core main flow rate $(\mathrm{kg} / \mathrm{s})$ & $\geq 86.4$ \\
Heavy metal loading per fuel element $(\mathrm{g})$ & 7 \\
Enrichment of fresh fuel element (for the equilibrium & 8.5 \\
core) (\%) & 3 \\
Active core diameter $(\mathrm{m})$ & 11 \\
Equivalent active core height $(\mathrm{m})$ & $\sim 6.0$ \\
Diameter of the RPV (m) & 420,000 \\
Number of fuel elements in one module & 15 \\
Number of fuel passages through the core & 90 \\
Average burnup $(\mathrm{GWd} / \mathrm{tU})$ & 13.9 \\
Main steam pressure $(\mathrm{MPa})$ & 571 \\
Main steam temperature $\left({ }^{\circ} \mathrm{C}\right)$ & 205 \\
Main feedwater temperature $\left({ }^{\circ} \mathrm{C}\right)$ &
\end{tabular}

shown in Figure 2, including the pebble-bed core, reflectors, carbon bricks, core vessel, RPV, water cooling panel of RCCS, and reactor building. In this model, the pebble-bed core, a porous medium with the void fraction of 0.39 , is divided into 6 nodes along the radius and 20 nodes along the height.

A 1D model for the primary circuit is also built and shown in Figure 3. In this model, rectangular figures represent the different components such as the hot-gas duct, the SG, and the blower, while circular figures are the nodal points used to connect the components. The $1 \mathrm{D}$ primary circuit model is through two nodal points ("core inlet" and "core outlet") connected to the 2D model via two corresponding components ("core inlet cavity" and "core outlet" shown in Figure 2).

In the below, one 2D model along with the connected $1 \mathrm{D}$ model is called as one TINTE model for a HTR-PM reactor module. To analyze the coupling behavior of the HTR-PM, two same models are built.

\section{VPOWER Code and Model}

4.1. vPower Code. The vPower code is an integrated simulation software developed by Beijing Neoswise Science and Technology Limited Company in China. The vPower code has user friendly interfaces (see Figure 4) based on Windows operation system and has many integrated, object-oriented graphical modeling tools, which can solve the built-in thermal fluid networks and electrical power flow networks. Powerful toolboxes are capable of simulating typical components of power plants, such as pipes, valves, steam turbines, deaerators, pumps, condensers, separators, and a variety of heat exchangers. Control systems and electrical supply of those components also have respective toolboxes. Moreover, the vPower code also supplies graphical tools to draw digital operating interfaces. Well-organized code architecture creates levels of data management and time schedule [5] and makes the vPower code widely serve for many simulators of coal-fired plants in China.

Moreover, the vPower code has unique functions of embedding a series of user-developed models, which extends the application of the vPower code into NPP simulators. Since 2009, Tsinghua University employed the vPower code to establish the HTR-PM engineering simulator by developing typical models of reactor core neutronics, helium flow, fuel pebbles, graphite blocks, helium circulators, oncethrough helical coil SGs, and control rods. Besides the newly developed models of the nuclear island, the conventional island components, as well as necessary human machine interfaces (HMIs), were also developed to form the full- 


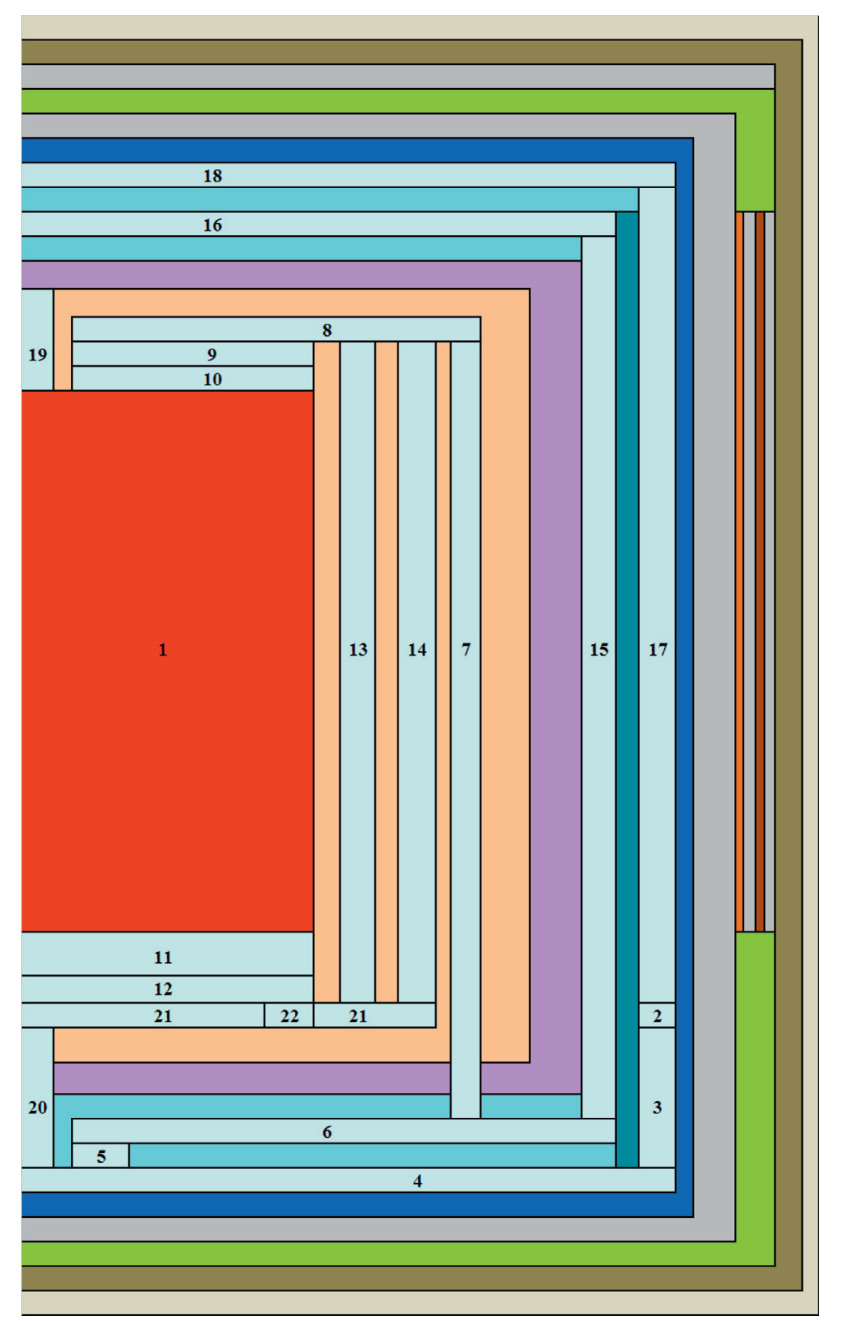

Fluid area

1: core;

2: core inlet cavity;

3: core inlet channel;

4: RPV bottom cavity;

5: RPV bottom flow passage;

6: core bottom cavity;

7: coolant channel;

8: cold helium plenum;

9: top reflector flow passage;

10: core top cavity;

Solid area

$\begin{array}{ll}\square \text { Graphite reflector; } & \square \text { Water cooling panel; } \\ \square \text { Carbon brick; } & \square \text { Metallic plate; } \\ \square \text { Metal internals; } & \square \text { Thermal insulation; } \\ \square \text { Core barrel; } & \square \text { Concrete wall; } \\ \square \text { RPV; } & \square \text { Air boundary. } \\ \square \text { Air gap; } & \end{array}$

FIgURE 2: $2 \mathrm{D}$ TINTE model of the HTR-PM reactor in $r-z$ coordinates.

scope simulation capability. Great efforts have been made to balance the computational cost and model accuracy in two aspects. As one challenge, the neutronic behavior is described by the improved quasistatic method to solve the three-dimensional space-time dynamic equations. The efficient solver also contributes to get the solutions of each step fast enough [24]. The other challenge is from the complicated three-dimensional gas flow and heat transfer inside the reactor core. Since the built-in thermal fluid network assumes it as the combinations of many one-dimensional flow paths and heat transfer paths, flow network and heat transfer network models can represent the reactor core flow and heat transfer and save computational time significantly [25]. After 3 years of effort, the engineering simulator of HTR-PM was able to perform the normal operation conditions well and basic abnormal scenarios in real time [5]. Following that, the engineering simulator was used to simulate the start-up and shut-down processes of the HTR-PM NSSS modules step by step and supported the confirmation of commissioning programs and detailed procedures [26, 27].

4.2. vPower Model of HTR-PM. The HTR-PM engineering simulator models by the vPower code mainly consist of reactor core section, SG, secondary loop section, control system, and electric system. The reactor core section has been described in many previous papers [5, 24, 25, 27]. In the current paper, the SG model and the secondary loop section are introduced to be coupled with the TINTE model of reactor core.

Each NSSS module of the HTR-PM has independent SG using helical coil heat transfer tube bundles. The engineering simulator developed a new component model of the helical coil heat transfer tube bundle to calculate the pressure drops and heat transfers in both the helium flow side and the steam/ water side, as well as the heat transfer from helium to steam/ water through the tube walls [26], shown in Figure 5(a). The matrix of SG model shows the configuration of 19 bundles, each one of which is divided into 16 subsections in height. In Figure 5(b), $19 \times 16$ components are connected by flow nodes and flow links to simulate helium flows in the primary side, while in Figure 5(c), the same components are again connected in the secondary side to simulate water/steam flows. The reuse of the SG component model can couple the calculations of flow and heat transfer of primary and secondary sides. Correlations of pressure drop and convection in both the primary and secondary sides were also described in [28]. Since the function of SG is significant to transfer reactor core heat into water/steam flow, the SG model is key to couple nuclear and conventional islands. In the engineering simulator of the HTR-PM, the vPower code is carefully tested and agrees well with design data $[27,28]$.

Seen from Figure 1, the water/steam side of SG serves as part of secondary side of the HTR-PM NPP. The engineering simulator of the HTR-PM also establishes models for components of the high-pressure and low-pressure cylinders of the steam turbine, the condenser, the condensate pumps, the low-pressure and high-pressure heaters, the deaerator, feedwater pumps, and many valves. These components are connected by one-dimensional pipes to form the complete water/steam flow network, which is solved by built-in thermal fluid solver. Several HMIs indicate more details of the secondary side models in Figures 6 and 7. Models and operation data of the secondary side of HTR-PM engineering simulator were also carefully tested to match the 


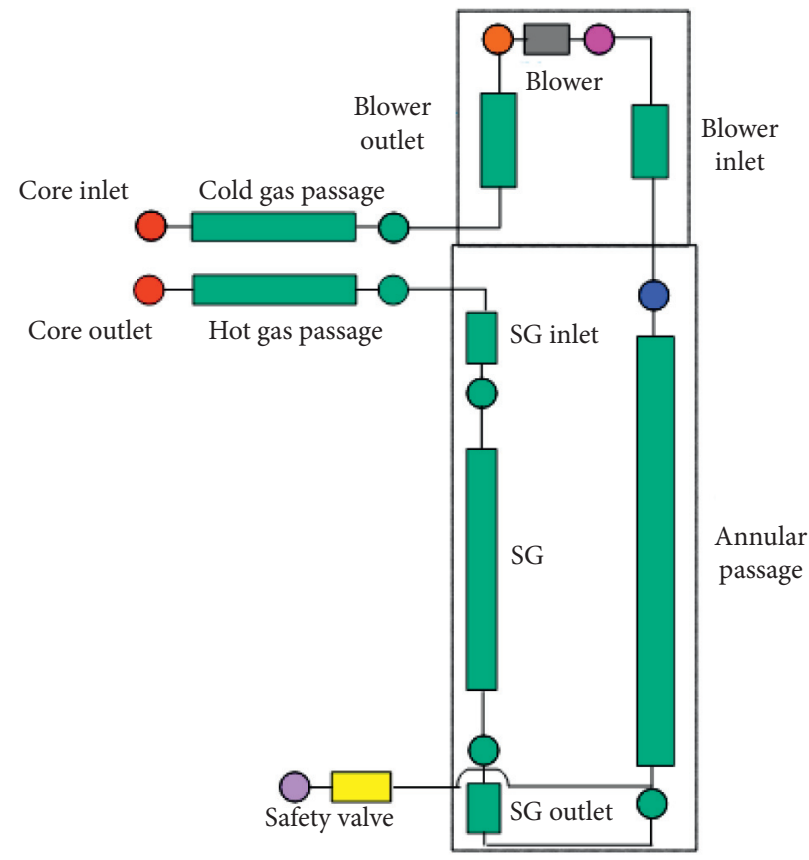

Figure 3: 1D TINTE model of the HTR-PM primary circuit.

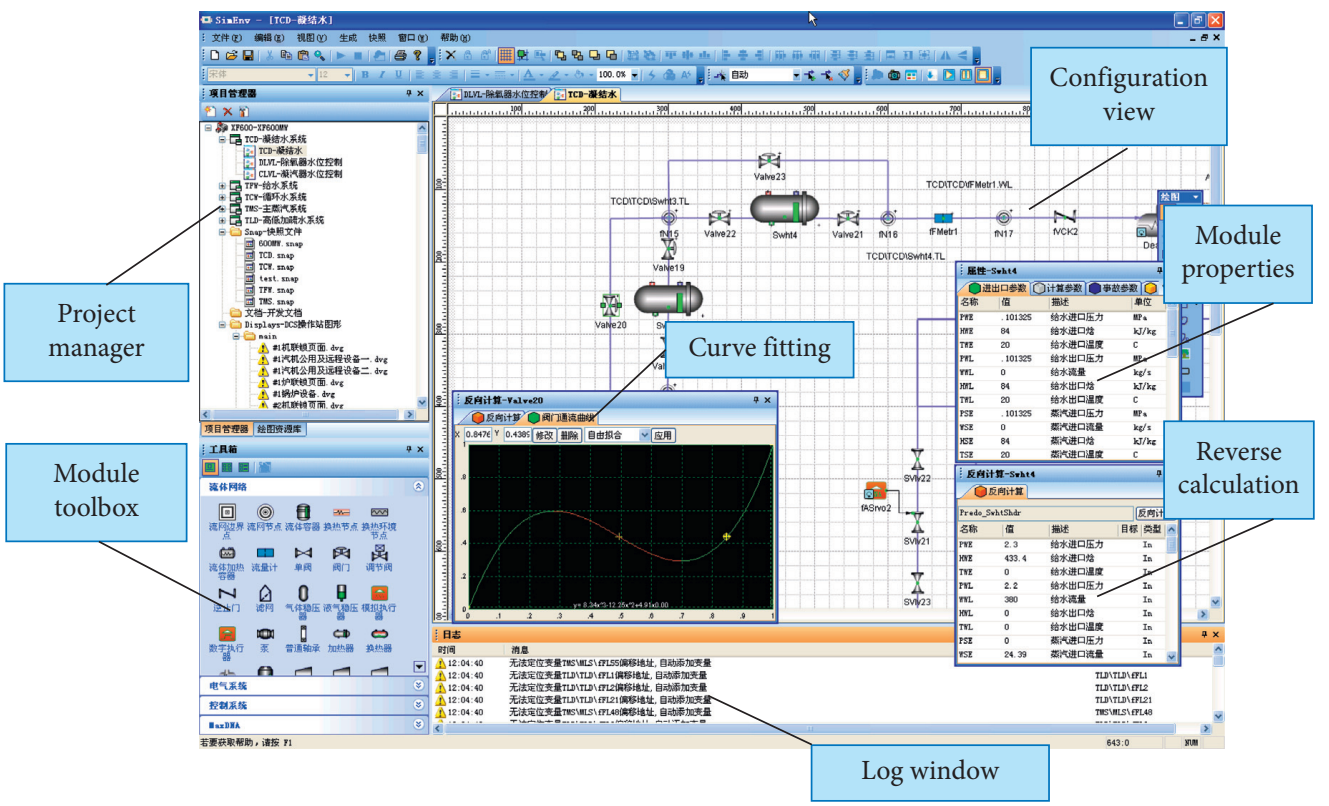

FIGURE 4: Interface of vPower code.

design parameters, which can continue to support the coupling with the TINTE code.

\section{Coupling between Different Circuits}

A coupling code package based on TINTE code and vPower code has been developed to study the coupling characteristics of the HTGR plants with more than one reactor module, and the data communication between these two codes can be controlled by an independent platform. In
HTR-PM analysis, two TINTE models are connected to one vPower model.

Coupling method between different circuits with these two codes can be explained as follows:

(1) Two TINTE models are, respectively, connected to one vPower model through the SG components, as shown in Figure 8.

(2) In the TINTE model, only the behavior of reactor core and primary circuit is analyzed, which means the heat load $Q$ (the heat transferred from the helium 

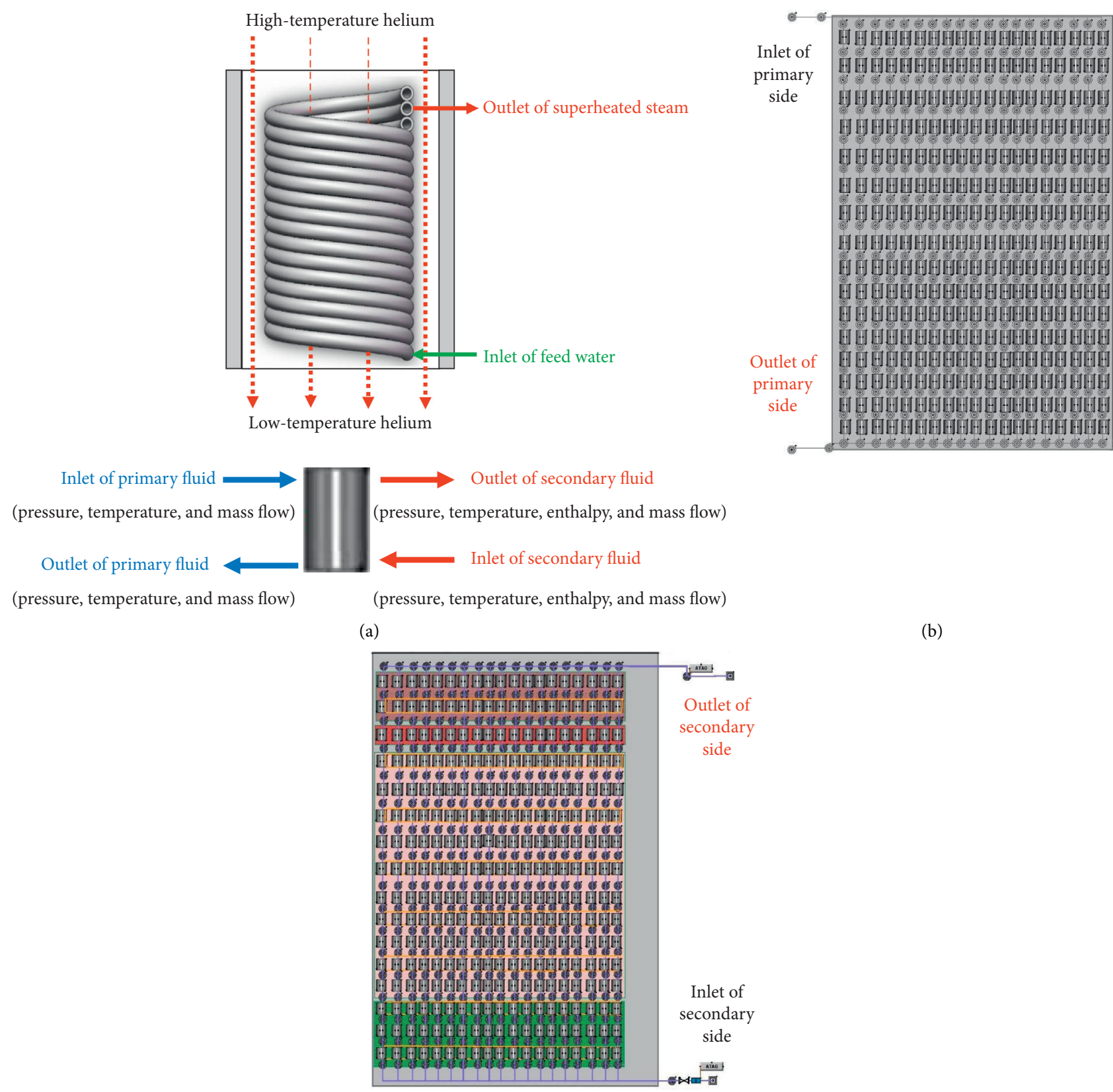

(c) (b)

FIGURE 5: The matrix model of SG in vPower code: (a) the typical bundle and its model of vPower code; (b) SG model of the primary side; (c) SG model of the secondary side.

side to the water/steam side in the SG) needs to be set as a boundary condition.

(3) In the vPower model, the behavior of the secondary circuit, but also including the helium side of the SG, will be analyzed. With the given value of the inlet temperature $\left(T_{\text {in }}\right)$, inlet pressure $\left(P_{\text {in }}\right)$, and mass flow rate $(F)$ in the helium side, the heat transfer between the primary circuit and the secondary circuit can be calculated.

(4) A steady state needs to be achieved firstly.
To perform a steady-state calculation, for example, for the HTR-PM in normal operation of $100 \%$ rated power, some input parameters should be set according to the design, including the heat reactor nuclear power, the SG heat load $(Q)$, the helium mass flow rate $(F)$, and core inlet helium temperature $\left(T_{\text {out }}\right)$ for two TINTE models, as well as the SG inlet helium temperature $\left(T_{\mathrm{in}}\right)$, SG inlet feedwater temperature, helium mass flow rate $(F)$, and feedwater mass flow rate for one vPower model. The resistance coefficients in the above models also need to be 


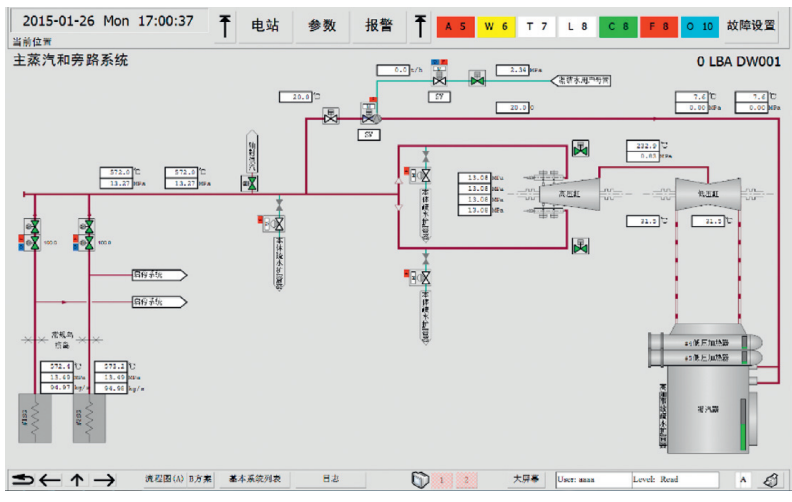

Figure 6: HMI for the main steam system in vPower code.

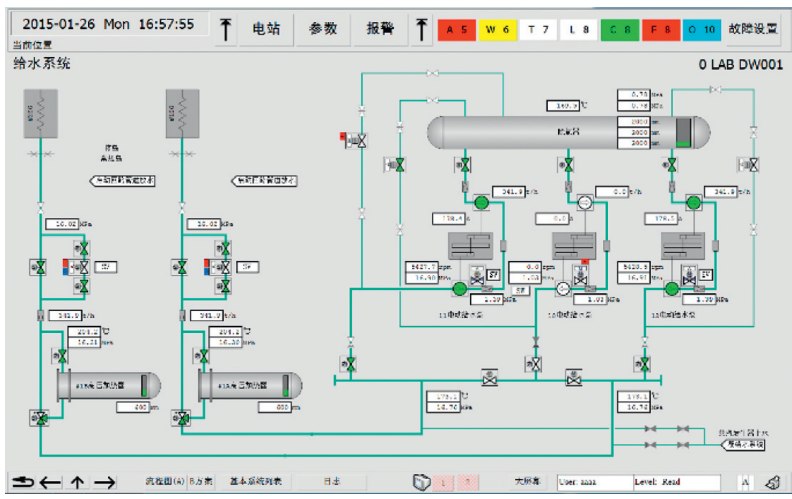

Figure 7: HMI for the feedwater system in vPower code.

adjusted according to the design so as to get the correct pressure drops.

Thus, an initial steady state for TINTE models and vPower model can be reached, and the values of $Q, F$, $T_{\text {in }}$, and $T_{\text {out }}$ in different models are consistent.

(5) During the transient calculation, for example, in the time point $t_{0}$, calculation will firstly be performed in two independent TINTE codes. Then, the calculation results of each module, including the SG inlet helium temperature $\left(T_{\text {in }}\right)$, inlet pressure $\left(P_{\text {in }}\right)$, and helium mass flow rate $(F)$, will be transmitted to act as the input data of the corresponding SG component, and the calculation will be performed by the vPower code. Finally, the calculation results of the vPower code, including the SG heat load (Q) and the SG outlet temperature $\left(T_{\text {out }}\right)$, will be transmitted back to the TINTE model and act as the input data for calculation of next time point.

(6) After calculation in a certain time point has finished, TINTE code can self-adjust the next time step, $\Delta t$, according to the calculation error. In this code package, after calculation in the time point $t_{0}$ has finished, two time steps, $\Delta t_{1}$ and $\Delta t_{2}$, will be given by two independent TINTE codes. The platform then will compare these two time steps and select the smaller one to determine the time point for next TINTE and vPower calculation.

\section{Calculation Results}

It is assumed that both NSSS modules of HTR-PM are initially operated in $100 \%$ rated power when an unexpected transient or perturbation occurs in the \#2 module. Two cases are simulated in this paper:

Case 1: the primary flow rate decreases linearly from $100 \%$ to $80 \%$ rated flow rate in 15 minutes

Case 2: a negative reactivity of $0.1 \% \Delta k / k$ is introduced in 2 minutes linearly

These cases aim to test the ability of this coupling code package to analyze the interaction behavior between two modules. The possible operator action, as well as the automatic response of the reactor protection system, is not considered.

6.1. Primary Flow Rate Decrease in Module One. Figures 9-14 show some calculation results of case 1 . The decrease in the primary flow rate will result in the decrease of the heat quantity transferred from the primary helium side to the secondary water/steam side in the SG, as shown in Figure 9 (dashed line). The heat transfer between the reactor core and primary coolant is also impaired, resulting in the increase in the fuel temperature, as shown in Figure 10. It also can be seen that the increase in the average fuel temperature during the first several minutes is very small, which is due to the 


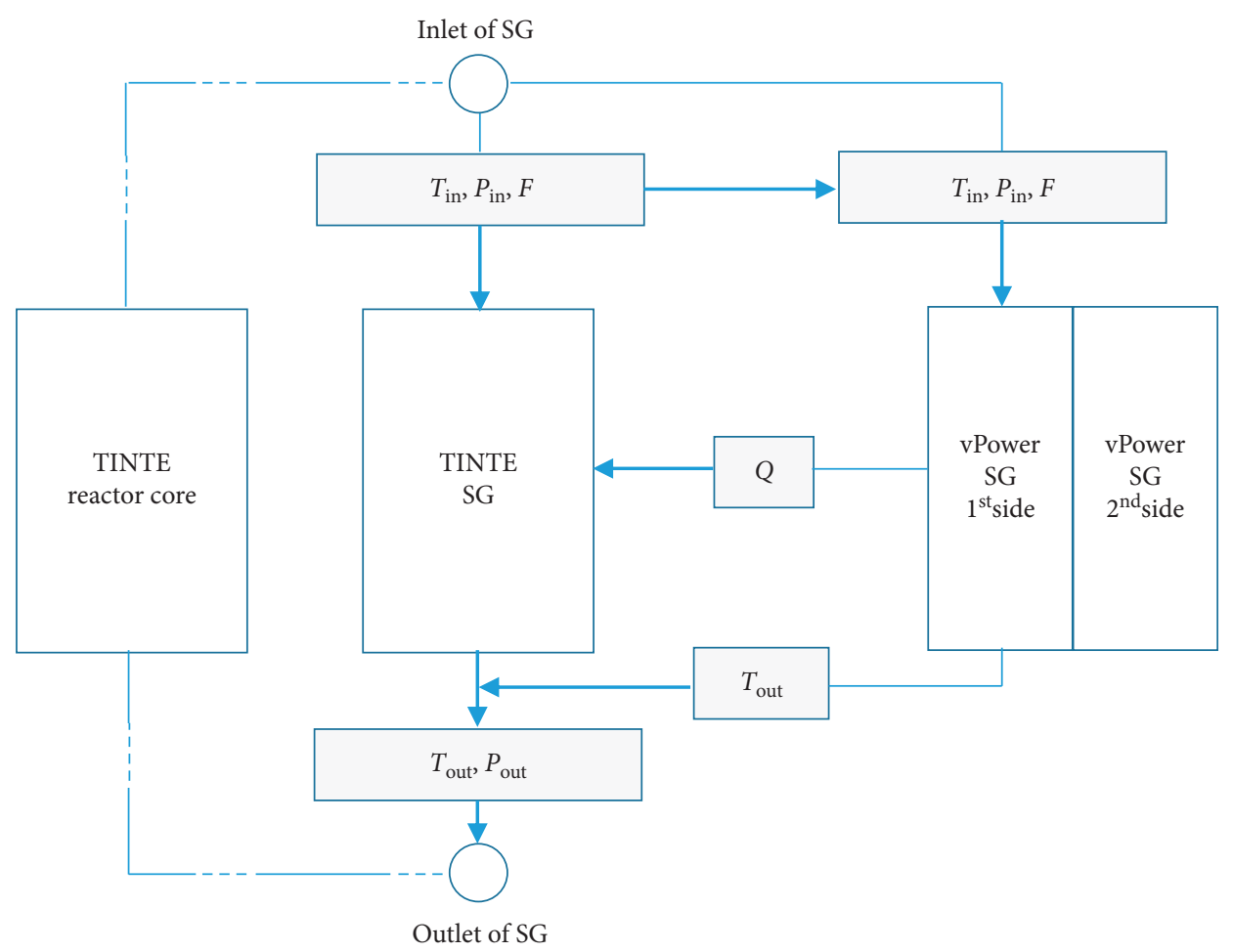

FIgURE 8: Coupling and data communication between TINTE and vPower.

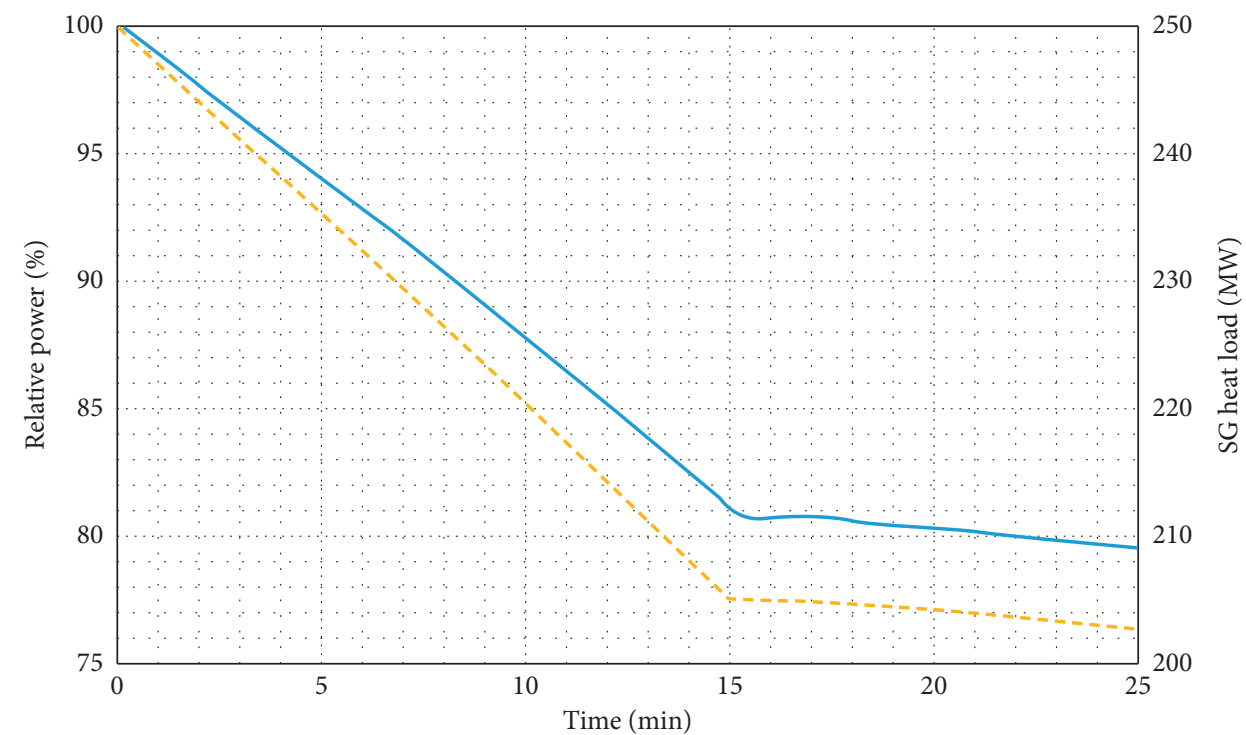

FIGURE 9: Relative power and SG heat load of \#2 module in case 1 (solid line: relative power; dashed line: SG heat load).

large heat capacity of the HTR-PM core (totally about $80 \mathrm{t}$ fuel elements and $250 \mathrm{t}$ reflector graphite in one reactor module). With the increase in the fuel temperature, the reactor power will decrease by negative temperature feedback, as the solid line in Figure 9 shows, which will result in the subsequent decrease in the average fuel temperature.

In the HTR-PM, primary coolant flows from the top to the bottom in the pebble-bed core and the maximum fuel temperature appears at the bottom of the core. With the decrease in the primary helium flow rate, the maximum fuel temperature and the resulting core outlet (namely, the SG inlet) helium temperature will increase continuously, but very slowly, as the dashed lines in Figures 10 and 11 show. These two curves begin to decline in about 15 minutes affected by the power decrease. It also can be seen from Figure 11 that, because of the larger mass flow rate of the secondary side compared to that of the primary side, the SG outlet helium temperature will decrease continuously.

As in the HTR-PM, the steam from two SGs will converge and then flow into one turbine, and the power decrease 


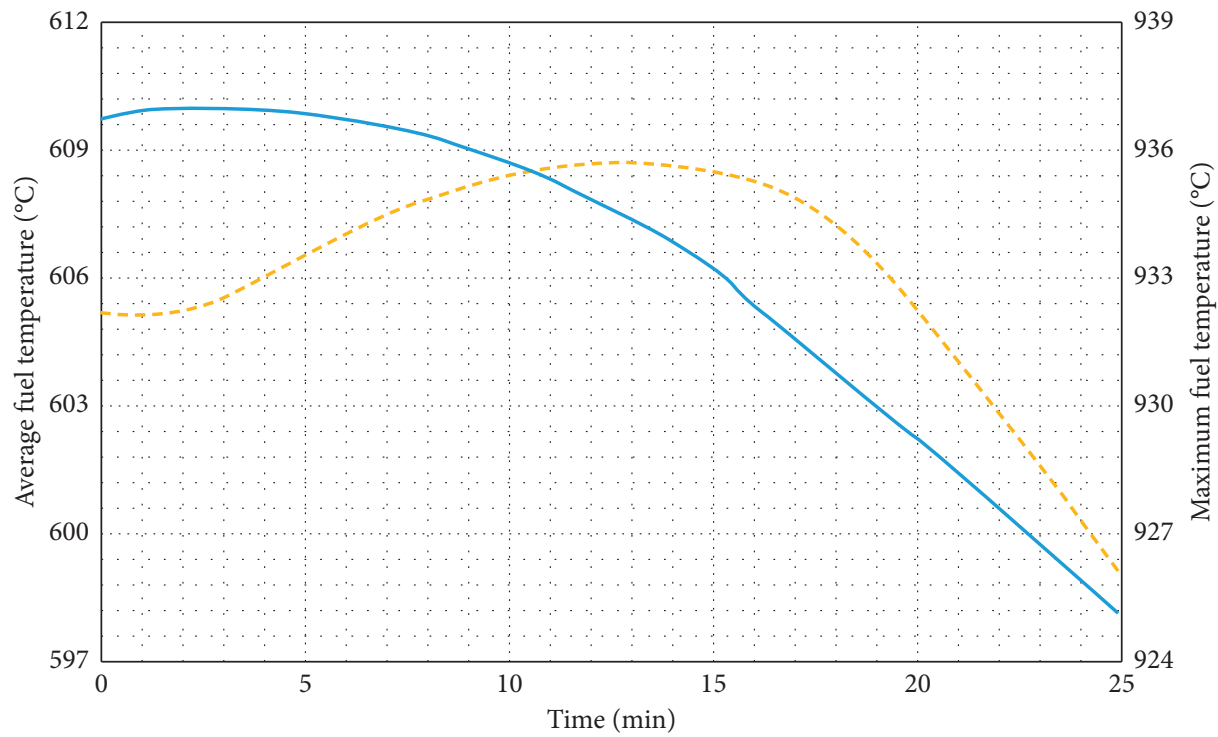

Figure 10: Average and maximum fuel temperature of $\# 2$ module in case 1 (solid line: average; dashed line: maximum).

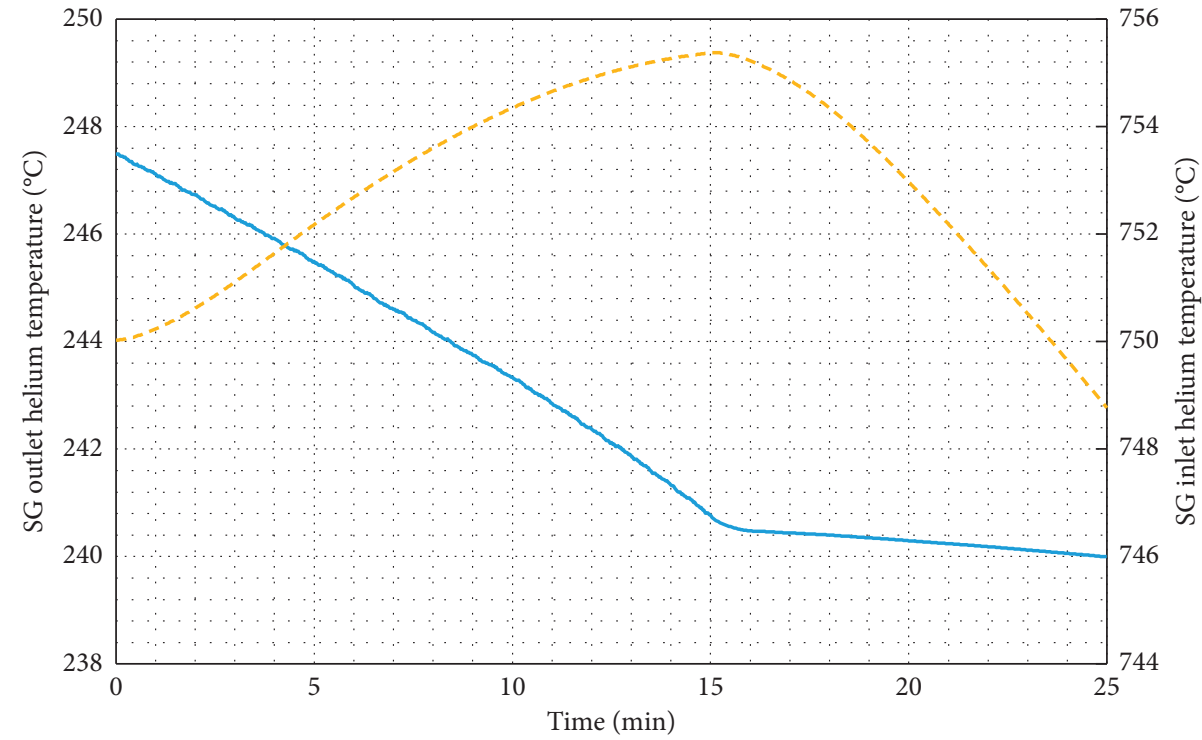

FIgURE 11: SG outlet and inlet helium temperature of \#2 module in case 1 (solid line: outlet; dashed line: inlet).

in \#2 module will also result in the small decrease in the feedwater temperature back to the SGs (as shown in Figure 12), so as to result in the small decrease in the SG outlet helium temperature in $\# 1$ module (Figure 13). The helium flows back to the reactor core with a little lower temperature and will then cause a little increase in the reactor power in \#1 module due to the negative temperature feedback (Figure 14).

6.2. Reactivity Introduction of Module One. In this case, a negative reactivity of about $0.1 \%$ is introduced into $\# 2$ module in 2 minutes, resulting in decrease in power (solid line in Figure 15) and the consequent decrease in fuel temperature (Figure 16) and core outlet helium temperature (dashed line in Figure 17, the SG inlet helium temperature).
The decrease in the SG inlet helium temperature will also cause the decrease in outlet helium temperature after it transfers the heat to the water/steam in the secondary circuit and flows back to the reactor (solid line in Figure 17).

It can be seen from Figure 17 that the core outlet helium temperature will decrease from about $750^{\circ} \mathrm{C}$ to less than $720^{\circ} \mathrm{C}$ in 20 minutes due to the decrease in the reactor power, while the decrease in the SG outlet helium temperature is only about several degrees. This can be explained by the coinstantaneous decrease in the heat transfer capacity between two sides of the SG, as the dashed line in Figure 15 shows.

As shown in Figure 15, the reactor power will rise over again due to the fuel temperature decrease and the resulting negative temperature feedback. After a little fluctuation, the 


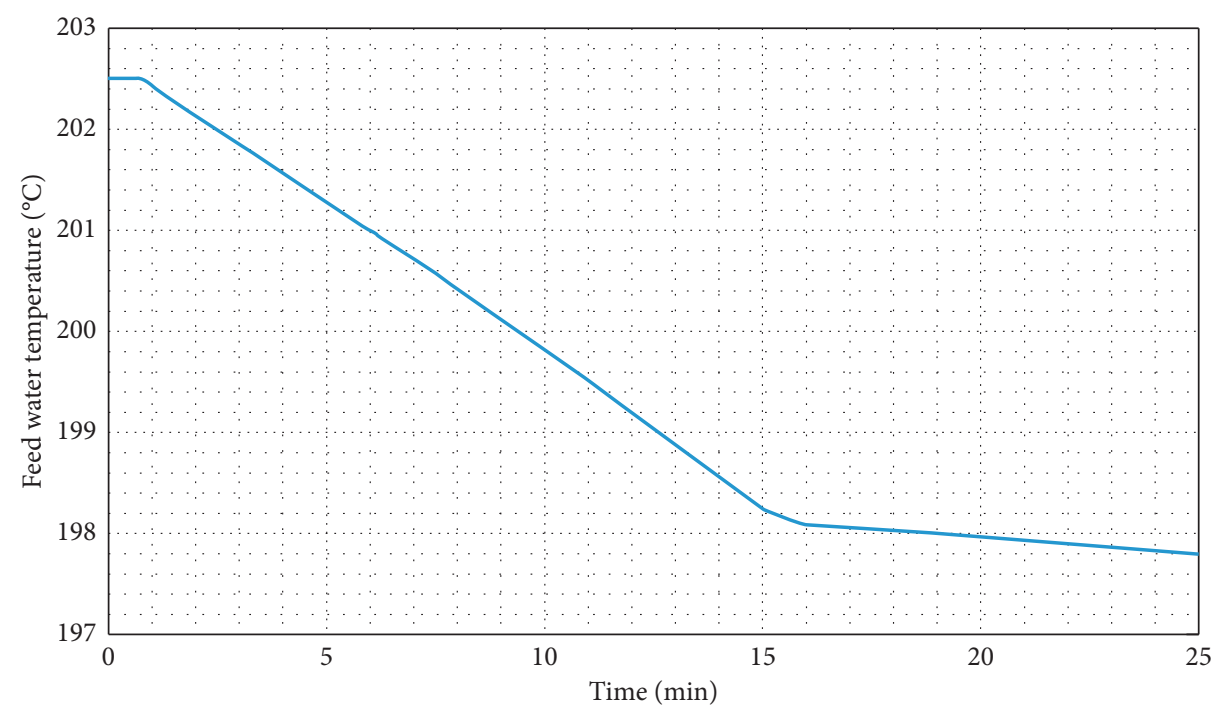

Figure 12: Feedwater temperature in case 1.

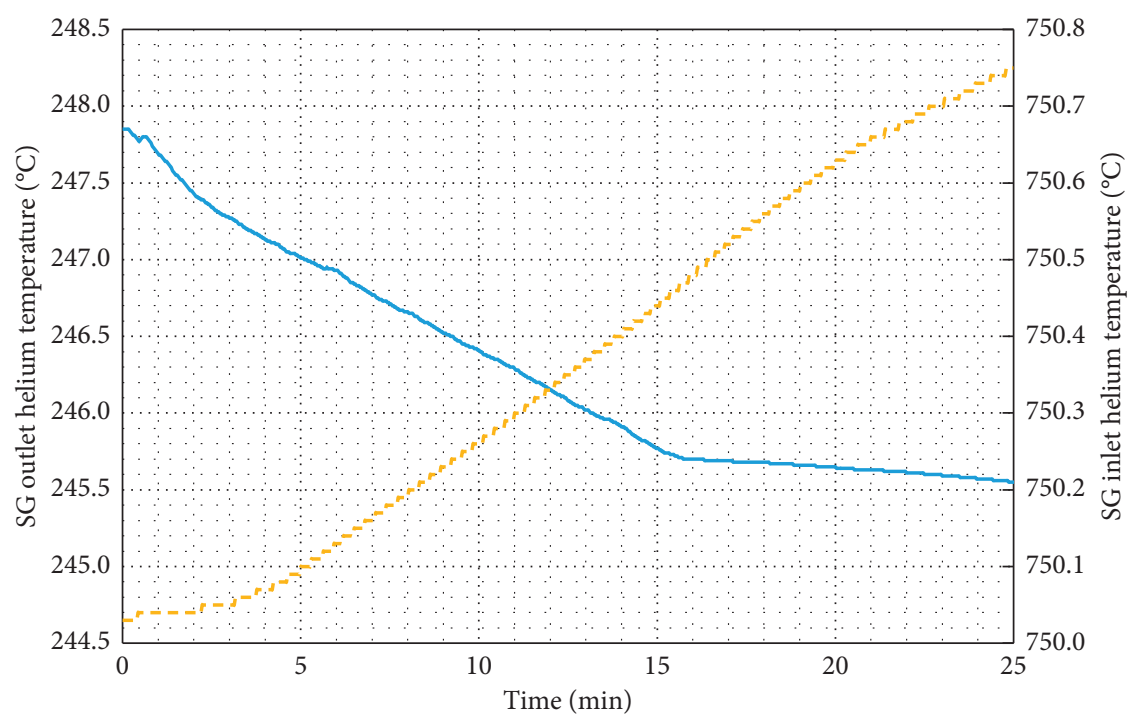

FIGURE 13: SG outlet and inlet helium temperature of \#1 module in case 1 (solid line: outlet; dashed line: inlet).

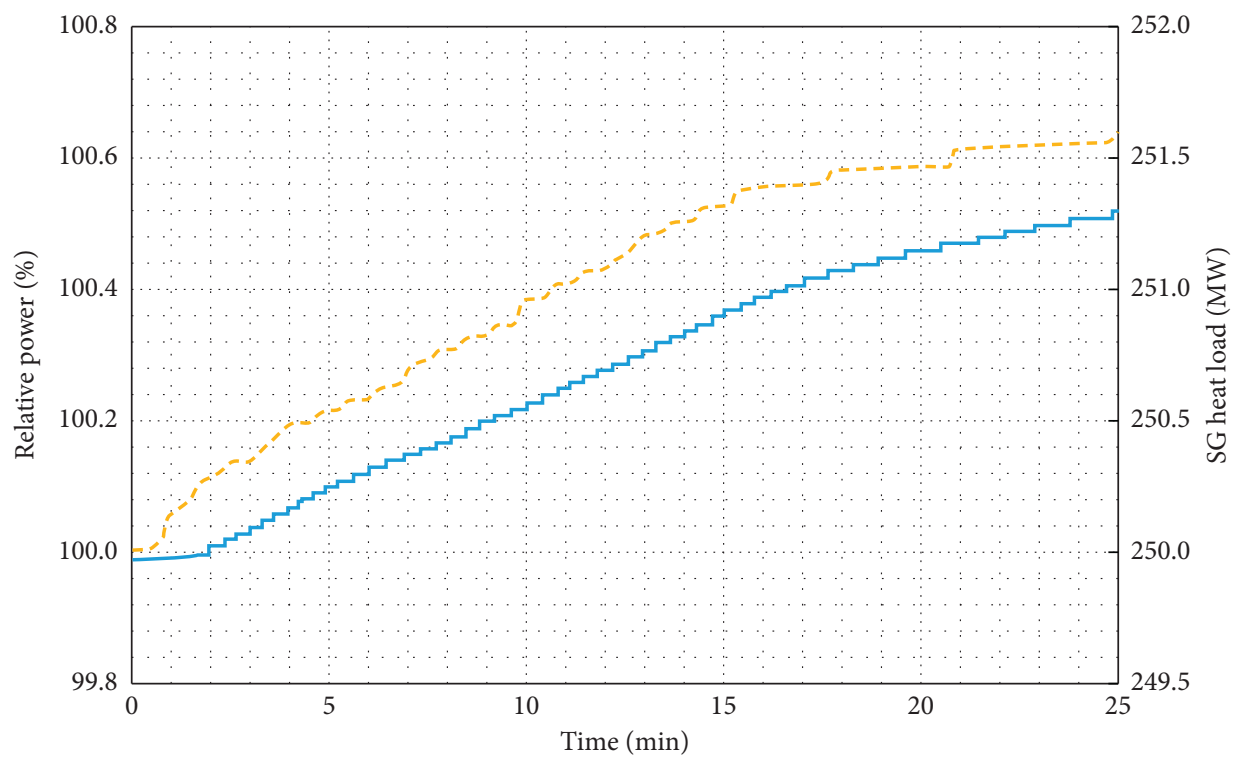

FIGURE 14: Relative power and SG heat load of \#1 module in case 1 (solid line: relative power; dashed line: SG heat load). 


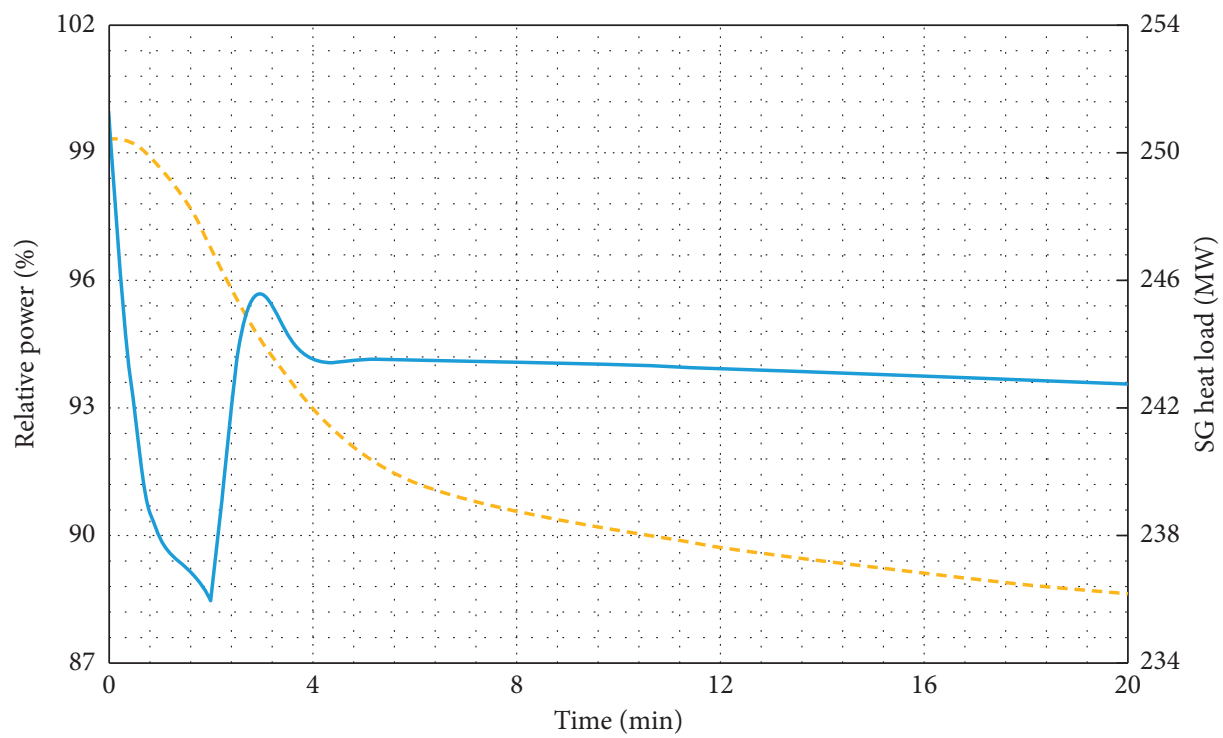

FIGURE 15: Relative power and SG heat load of \#2 module in case 2 (solid line: relative power; dashed line: SG heat load).

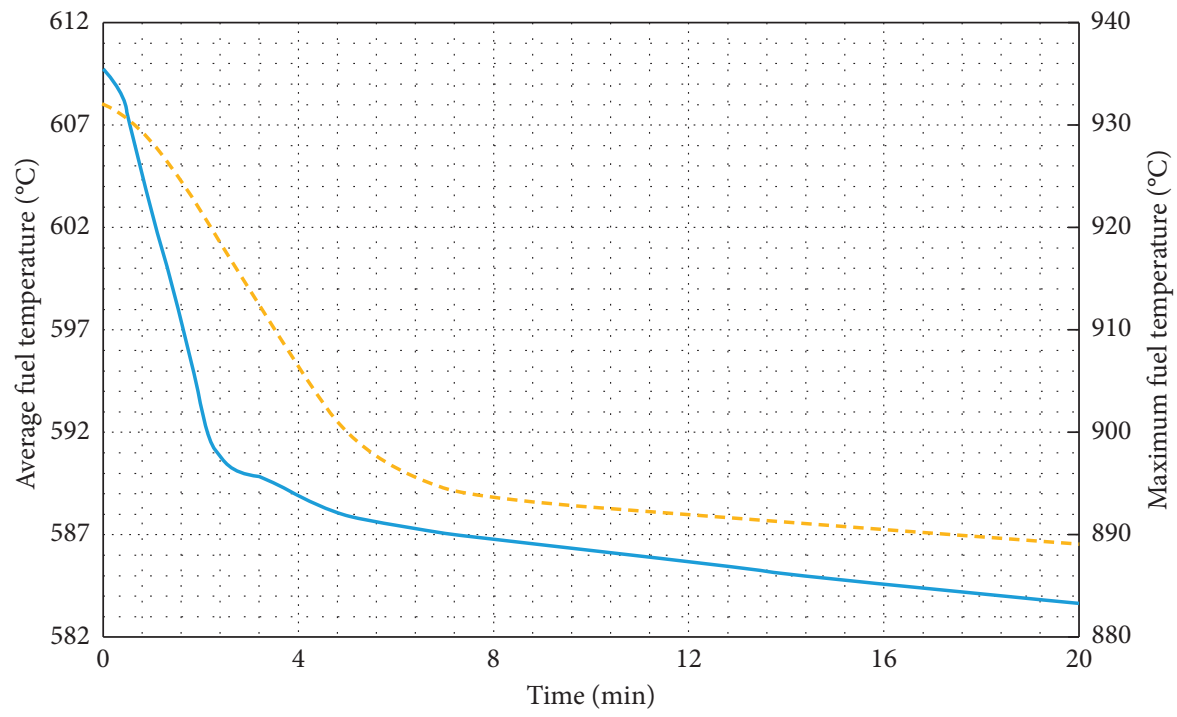

Figure 16: Average and maximum fuel temperature of \#2 module in case 2 (solid line: average; dashed line: maximum).

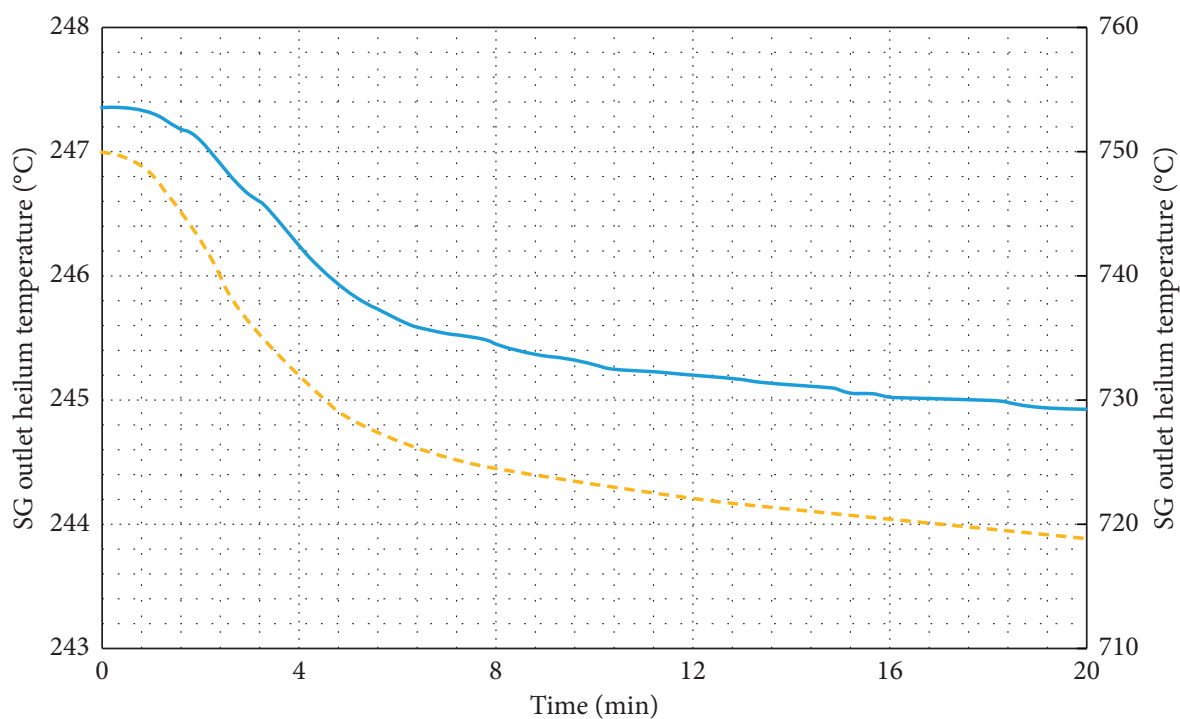

FIGURE 17: SG outlet and inlet helium temperature of \#2 module in case 2 (solid line: outlet; dashed line: inlet). 


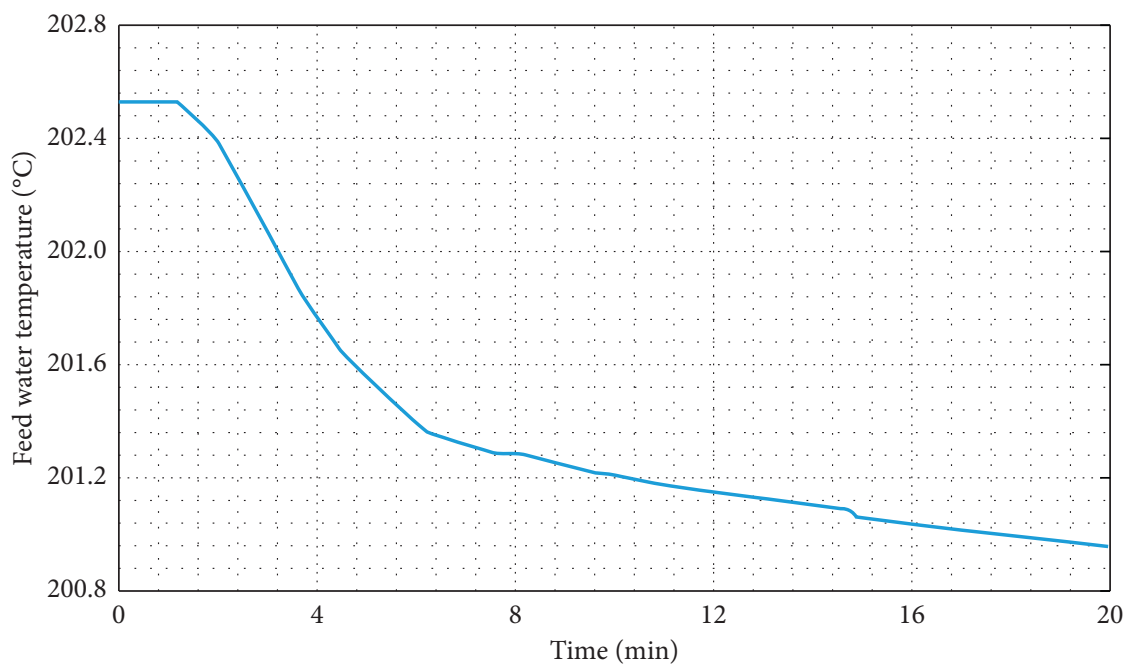

FIgURE 18: Feedwater temperature in case 2.

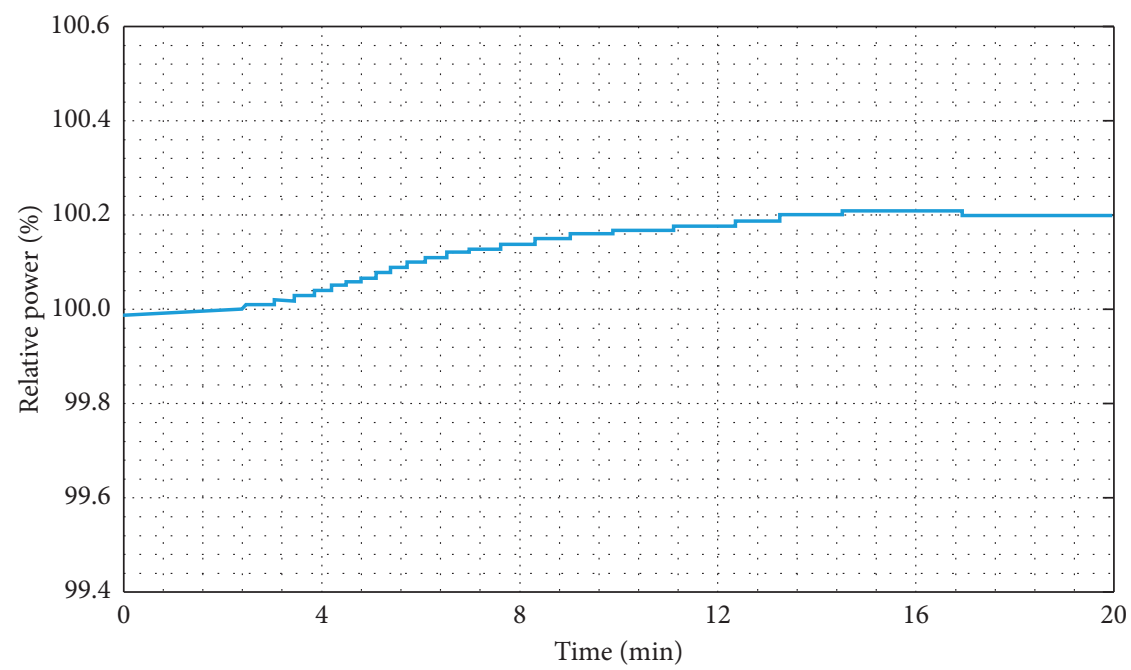

FIGURE 19: Relative power of \#1 module in case 2.

power maintains a stable value lower than the initial rated power.

Again, the power decrease in \#2 module will result in the small decrease in the feedwater temperature back to the SGs (Figure 18), so as to result in the small decrease in the SG outlet helium temperature in \#1 module. The helium flowing back to the reactor core with a little lower temperature will then cause a little increase in the reactor power in \#1 module due to the negative temperature feedback (Figure 19).

\section{Summary and Conclusion}

The modular HTGR is recognized as a candidate for the generation IV nuclear energy system technology and has well-known inherent safety features. The commercialscale 200 MW HTR-PM consists of two NSSS modules and one turbine. Furthermore, the design with more NSSS modules connected to one turbine will be considered in the future. It would be very important and necessary to understand the coupling characteristics between these modules, especially when some transients occur at part of the modules.

A coupling code package has been developed based on the TINTE code and vPower code. These two codes are connected through components of SG. TINTE code is used to carry out the analysis of reactor core and primary circuit, while vPower code performs the secondary circuit calculation, including the primary side of the SGs. A platform is used to transfer data between these two codes, including time steps.

Two cases, including the primary flow rate decrease and the negative reactivity introduction of one module, had been simulated with this code package, and the calculation results were introduced in this paper. The preliminary calculation results can explain the phenomena during the transients. It shows that the coupling code package has the ability to analyze the coupling and interaction behavior between two modules. 
Besides, the code package needs to be further improved and optimized, and more simulation should be performed. Further analysis on the coupling behavior between different modules would provide important support for the future development of the modular HTGRs.

\section{Nomenclature}

$c_{g}:$ Helium heat capacity

$T_{g}$ : Helium temperature

$c_{s}$ : Pebble-bed heat capacity

$T_{s}$ : Pebble-bed temperature

$d$ : Diameter of fuel element

$\vec{u}$ : Helium velocity

$\vec{g}$ : Gravity acceleration

$\alpha$ : Convective heat transfer coefficient

$\mathrm{Nu}$ : Nusselt number

$\varepsilon$ : Porosity of the pebble bed

$p$ : Helium pressure

$\rho_{g}:$ Helium density

Pr: Prandtl number

$\rho_{s}: \quad$ Pebble-bed density

$q_{s}$ : Heat flux from the fuel element

$\lambda_{f}$ : Pebble-bed effective thermal conductivity

Re: Reynolds number

$\lambda_{g}$ : Helium thermal conductivity.

\section{Data Availability}

The data used to support the finding of this study, for example, the data used to build the model of HTR-PM, have not been made available because these belong to engineering design parameters and could not be available at present.

\section{Conflicts of Interest}

The authors declare that they have no conflicts of interest.

\section{Acknowledgments}

This paper was supported by the National S\&T Major Project (Grant no. ZX06902013) and Tsinghua University Initiative Scientific Research Program (20197050014).

\section{References}

[1] Z. Zhang and Y. Sun, "Economic potential of modular reactor nuclear power plants based on the Chinese HTR-PM project," Nuclear Engineering and Design, vol. 237, no. 23, pp. 22652274, 2007.

[2] Z. Zhang, Z. Wu, D. Wang et al., "Current status and technical description of Chinese $2 \times 250$ MWth HTR-PM demonstration plant," Nuclear Engineering and Design, vol. 239, no. 7, pp. 1212-1219, 2009.

[3] D. Liu, J. Sun, Y. L. Sun, X. L. Xu, Z. Sui, and Y. L. Ma, “A preliminary Research for the operating characteristics of the multi-module nuclear reactor system," 2015.

[4] D. Liu, J. Sun, Z. Sui, X. L. Xu, Y. L. Ma, and Y. L. Sun, "Modeling and simulation of the multi-module high temperature gas-cooled reactor," Proceedings of the HTR, vol. 239, 2014.
[5] Z. Sui, J. Sun, C. Wei, and Y. Ma, "The engineering simulation system for HTR-PM," Nuclear Engineering and Design, vol. 271, pp. 479-486, 2014.

[6] Y. Zheng, L. Shi, and Y. Dong, “Thermohydraulic transient studies of the Chinese 200MWe HTR-PM for loss of forced cooling accidents," Annals of Nuclear Energy, vol. 36, no. 6, pp. 742-751, 2009.

[7] Y. Zheng, J. Lapins, L. Shi, and Z. Zhang, "Thermal hydraulic analysis of a pebble-bed modular high temperature gas-cooled reactor with ATTICA3D and THERMIX codes," Nuclear Engineering and Design, vol. 246, pp. 286-297, 2012.

[8] H. Laurien, W. Scherer, and E. Teuchert, "The TINTE modular code system for computational simulation of transient processes in the primary circuit of a pebble-bed high-temperature gas-cooled reactor," Nuclear Science and Engineering, vol. 103, no. 3, pp. 302-312, 1989.

[9] W. Scherer, H. Gerwin, T. Kindt et al., "Analysis of reactivity and temperature transient experiments at the AVR hightemperature reactor," Nuclear Science and Engineering, vol. 97 , no. $58,1987$.

[10] Y. Sun and H. Genrvln, "On the validation of the reactor-dynamics code system TINTE post calculation of the experiment SANA-I with a central heating element," KFA-IB-93-13, vol. 97, 1987.

[11] Y. Sun, "Voruntersuchungen zum experiment NACOK mit dem reaktordynamik-programm TINTE," KFA-ISR-IB-14/93, vol. 97, 1993.

[12] Y. Zheng, L. Shi, and Y. Wang, "Water-ingress analysis for the 200MWe pebble-bed modular high temperature gas-cooled reactor," Nuclear Engineering and Design, vol. 240, no. 10, pp. 3095-3107, 2010.

[13] P. Liu, Z. Chen, Y. Zheng et al., "Study on air ingress of the 200 MWe pebble-bed modular high temperature gas-cooled reactor," Annals of Nuclear Energy, vol. 98, pp. 120-131, 2016.

[14] Z. Chen, X. Chen, Y. Zheng et al., "Air ingress analysis of chimney effect in the 200 MWe pebble-bed modular high temperature gas-cooled reactor," Annals of Nuclear Energy, vol. 106, pp. 143-153, 2017.

[15] H. Gerwin, Das zweidimensionale reaktordynamikprogramm TINTE, Teil: Grundlagen und Lösungsverfahren. Jül-2167, Kernforschungsanlage JülichGmbH, New York, NY, USA, 1987.

[16] H. Zhang and J. Guo, "The improvement of coupling method in TINTE by fully implicit scheme," Nuclear Science and Engineering, vol. 98, 2018.

[17] K. Robold, Wärmetransport im inneren und in der randzone von kugelschüttungen, Jül-1796-RW, New York, NY, USA, 1982.

[18] P. Zehner and E. U. Schlünder, "Einfluss der wärmestrahlung und des druckes auf den wärmetransport in nichtdurchströmten schüttungen," Nuclear Science and Engineering, vol. 4, 1982.

[19] M. Schürenkrämer and H. Barthels, Experimentelle untersuchungen zur thermohydraulik in kugelschüttungen im vergleich mit dem rechenprogramm Thermix-2D. Die untersuchung des dispersiven wärmetransportes am beispiel einer kaltgassträhne, Jül-1839-RW, New York, NY, USA, 1983.

[20] H. Barthels and M. Schürenkrämer, Die effective wärmeleitfähigkeit in kugelschüttungen unter besonderer berücksichtigung des hochtemperatur-reaktors, Jül-1893-RW, New York, NY, USA, 1984.

[21] Y. Zheng, M. M. Stempniewicz, Z. Chen, and L. Shi, "Study on the DLOFC and PLOFC accidents of the 200 MWe pebble-bed modular high temperature gas-cooled reactor with TINTE 
and SPECTRA codes," Annals of Nuclear Energy, vol. 120, pp. 763-777, 2018.

[22] Y. Zheng, "Reactor core design of high-temperature gascooled reactors, Part 3: loss of pressure through friction in pebble bed cores," KTA3102, vol. 3, 1981.

[23] Y. Zheng, "Reactor core design of high-temperature gascooled reactors, Part 2: heat transfer in spherical fuel elements," KTA, vol. 2, 1983.

[24] C. Wei, Z. Sui, Y. Ma, X. Jing, and W. Shan, "Application of improved quasi-static method to high temperature gas cooled reactor simulator," Nuclear Engineering and Design, vol. 271, pp. 337-340, 2014.

[25] J. Sun, Z. Sui, C. L. Wei, Y. L. Ma, W. Z. Shan, and L. Shi, "Thermal hydraulic models of the HTR simulator," 2012.

[26] D. Liu, J. Sun, X. Xu, and Y. Sun, "Simulation and analysis of start-up process of high temperature gas-cooled reactor," Atomic Energy Science and Technology, vol. 48, pp. 594-598, 2014, (in Chinese).

[27] D. Liu, Research on the Operating Characteristics of MultiModule High Temperature Gas-cooled Nuclear Power Plants, Tsinghua University, London, UK, (in Chinese), 2015.

[28] D. Liu, J. Sun, and Y. Sun, "Modeling and analysis of oncethrough steam generator in HTR-PM," Atomic Energy Science and Technology, vol. 50, no. 6, pp. 995-1001, 2016, (in Chinese). 